\title{
Article
}

\section{Use of the Modified Riccati Technique for Neutral Half-Linear Differential Equations}

\author{
Zuzana Pátíková ${ }^{1, *(\mathbb{D})}$ and Simona Fišnarová ${ }^{2} \mathbb{D}$ \\ 1 Department of Mathematics, Tomas Bata University in Zlín, Nad Stráněmi 4511, 76005 Zlín, Czech Republic \\ 2 Department of Mathematics, Mendel University in Brno, Zemědělská 1, 61300 Brno, Czech Republic; \\ fisnarov@mendelu.cz \\ * Correspondence: patikova@utb.cz; Tel.: +420-57-603-5005
}

check for updates

Citation: Pátíková, Z.; Fišnarová, S. Use of the Modified Riccati Technique for Neutral Half-Linear Differential Equations. Mathematics 2021, 9, 235. https://doi.org/10.3390/math9030235

Academic Editor: Jozef Džurina Received: 28 December 2020 Accepted: 20 January 2021 Published: 25 January 2021

Publisher's Note: MDPI stays neutral with regard to jurisdictional clai$\mathrm{ms}$ in published maps and institutional affiliations.

Copyright: $\odot 2021$ by the authors. Licensee MDPI, Basel, Switzerland. This article is an open access article distributed under the terms and conditions of the Creative Commons Attribution (CC BY) license (https:// creativecommons.org/licenses/by/ $4.0 /)$.

\begin{abstract}
We study the second-order neutral half-linear differential equation and formulate new oscillation criteria for this equation, which are obtained through the use of the modified Riccati technique. In the first statement, the oscillation of the equation is ensured by the divergence of a certain integral. The second one provides the condition of the oscillation in the case where the relevant integral converges, and it can be seen as a Hille-Nehari-type criterion. The use of the results is shown in several examples, in which the Euler-type equation and its perturbations are considered.
\end{abstract}

Keywords: half-linear neutral differential equation; oscillation criteria; modified Riccati technique

MSC: 34K11; 34C10

\section{Introduction}

In this paper, we study the oscillatory properties of the second-order half-linear neutral differential equation

$$
\left(r(t) \Phi\left(z^{\prime}(t)\right)\right)^{\prime}+c(t) \Phi(x(\tau(t)))=0, \quad z(t)=x(t)+b(t) x(\sigma(t)),
$$

where $t \geq t_{0}$ and $\Phi(x)=|x|^{p-2} x, p \in \mathbb{R}$, and $p>1$. We suppose that the coefficients of the equation satisfy the usual conditions: $r \in C\left(\left[t_{0}, \infty\right), \mathbb{R}^{+}\right), b \in C^{1}\left(\left[t_{0}, \infty\right), \mathbb{R}_{0}^{+}\right)$, $c \in C\left(\left[t_{0}, \infty\right), \mathbb{R}_{0}^{+}\right), c$ is not identically equal to zero in any neighborhood of infinity, and

$$
b(t) \leq 1
$$

Concerning the deviating arguments, we assume that $\tau, \sigma \in C^{1}\left(\left[t_{0}, \infty\right), \mathbb{R}\right), \lim _{t \rightarrow \infty} \tau(t)=\infty$, $\lim _{t \rightarrow \infty} \sigma(t)=\infty$ and

$$
\tau^{\prime} \geq 0, \quad \tau(t) \leq t, \quad \sigma(t) \leq t
$$

We also suppose that

$$
\int^{\infty} r^{1-q}(t) d t=\infty
$$

where $q$ denotes the conjugate number of $p$, i.e., $q=\frac{p}{p-1}$, and the symbol $\int^{\infty}$ means that it does not matter what the lower limit of the integral is if it is large enough, and that the limit process is applied on the upper limit of the integral as it tends to infinity. The above setting and conditions (2)-(4) are intended to hold throughout this whole paper and in all of its statements.

A differential equation is called neutral if it contains the highest-order derivative of an unknown function both with and without delay. This means that the rate of growth depends on the current state and the state in the past, as well as on the rate of change in the past, which enables a suitable description for many real processes. For example, the process of 
growth of a human population ([1]) or a population of Daphnia magna ([2]) can be modeled by neutral differential equations. Neutral Equation (1) is called half-linear, as its solution space is homogenous but not additive (it only has half of the linearity properties), and it can also be classified as Emden-Fowler equation. Neutral half-linear/Emden-Fowler equations arise in a variety of real-world problems, such as in the study of $p$-Laplace equations, non-Newtonian fluid theory, the turbulent flow of a polytrophic gas in a porous medium, and so forth (see, for example, [3-6]).

In recent years, the qualitative theory of Equation (1) has attracted considerable attention, and it has been studied under condition (4), for example, in [7-11] (see also the references therein). For the case where the integral in (4) converges, let us refer to $[12,13]$. If $b(t) \equiv 0$, then the studied equation becomes a delayed half-linear equation, and its oscillation results are provided, for example, in [14-20].

By a solution of (1), we mean a differentiable function $x(t)$ that is eventually not identically equal to zero, such that $r(t) \Phi\left(z^{\prime}(t)\right)$ is differentiable and (1) holds for $t \geq t_{0}$. Equation (1) is said to be oscillatory if it does not have a solution that is eventually positive or negative.

In this paper, we formulate new oscillation criteria for Equation (1). One of them can be classified as a Hille-Nehari type statement. Our results are based on the modification of the Riccati technique. Instead of the usual Riccati inequality, we use the so-called modified Riccati inequality. The modified Riccati technique has been used in the theory of ordinary half-linear differential equations of the form

$$
\left(r(t) \Phi\left(x^{\prime}(t)\right)\right)^{\prime}+c(t) \Phi(x(t))=0,
$$

and it has been revealed that it is a useful tool that can be regarded as a replacement of the missing half-linear version of the transformation formula known from the classical oscillation theory of linear equations. For the related results concerning this method, we refer to [21-23] and the references given therein. We point out that, within the same approach, Hille-Nehari-type criteria for (5) were last studied in [24]. In Ref. [18], the modified Riccati technique was extended and applied to half-linear differential equations with delay:

$$
\left(r(t) \Phi\left(x^{\prime}(t)\right)\right)^{\prime}+c(t) \Phi(x(\tau(t)))=0 .
$$

Here, we show that the method can also be extended for neutral half-linear equations and used to derive some oscillation criteria for (1).

This paper is organized as follows. In the next section, we introduce the modified Riccati technique and formulate some preliminary results. In Section 3, we present our main results, the oscillation criteria for (1), and in the last section, we apply the results to a perturbed equation of the Euler type.

\section{Preliminaries}

We start with the properties of the eventually positive solutions of (1) that are ensured with condition (4). By the function $\Phi^{-1}$, we mean the inverse function to $\Phi$, i.e., $\Phi^{-1}(x)=$ $|x|^{q-2} x$.

Lemma 1. Suppose that $x(t)$ is a solution of (1) that is positive on $\left[t_{0}, \infty\right)$. Then, there exists $T>t_{0}$ such that

$$
\begin{gathered}
z(t)>0, \quad z^{\prime}(t)>0, \quad\left(r(t) \Phi\left(z^{\prime}(t)\right)\right)^{\prime} \leq 0, \\
\frac{z^{\prime}(\tau(t))}{z^{\prime}(t)} \geq \Phi^{-1}\left(\frac{r(t)}{r(\tau(t))}\right)
\end{gathered}
$$

and

$$
\left(r(t) \Phi\left(z^{\prime}(t)\right)\right)^{\prime} \leq-c(t) \Phi[z(\tau(t))(1-b(\tau(t))]
$$

for $t \geq T$. 
Proof. Condition (7) is a well-known statement and its proof can be found, e.g., in [7] (Lemma 3). Because $r(t) \Phi\left(z^{\prime}(t)\right)$ is non-increasing, we have

$$
r(t) \Phi\left(z^{\prime}(t)\right) \leq r(\tau(t)) \Phi\left(z^{\prime}(\tau(t))\right),
$$

which can be rearranged into (8). Now, we observe that $x(\sigma(\tau(t))) \leq z(\sigma(\tau(t))) \leq z(\tau(t))$ and, in view of (1),

$$
\begin{aligned}
0= & \left(r(t) \Phi\left(z^{\prime}(t)\right)\right)^{\prime}+c(t) \Phi[z(\tau(t))-b(\tau(t)) x(\sigma(\tau(t)))] \\
& \geq\left(r(t) \Phi\left(z^{\prime}(t)\right)\right)^{\prime}+c(t) \Phi[z(\tau(t))(1-b(\tau(t)))],
\end{aligned}
$$

which implies (9).

Grace et al. showed in [10] that, under some additional assumptions, condition (8) can be strengthened. Similarly to in [25], they considered the sequence

$$
g_{0}(\varrho):=1, \quad g_{n+1}(\varrho):=e^{\varrho g_{n}(\varrho)}, \quad n=0,1,2, \ldots,
$$

where $\varrho$ is a positive constant. For $\varrho \in\left(0, \frac{1}{e}\right]$, the sequence is increasing and bounded above, and $\lim _{t \rightarrow \infty} g_{n}(\varrho)=g(\varrho) \in[1, e]$, where $g(\varrho)$ is a real root of the equation

$$
g(\varrho)=e^{\varrho g(\varrho)} .
$$

With the use of this sequence and the notation

$$
\begin{aligned}
& \mathcal{Q}(t):=\Phi(1-b(\tau(t))) c(t), \quad \mathcal{R}(t):=\int_{t_{1}}^{t} r^{1-q}(s) d s, \\
& \tilde{\mathcal{R}}(t):=\mathcal{R}(t)+\frac{1}{p-1} \int_{t_{1}}^{t} \mathcal{R}(s) \Phi(\mathcal{R}(\tau(s))) \mathcal{Q}(s) d s
\end{aligned}
$$

for $t \geq t_{1}$, where $t_{1}$ is large enough, Grace et al. proved the following lemma.

Lemma 2 ([10], Lemma 4). Assume that $\tau$ is strictly increasing, Equation (1) has a positive solution $x(t)$ on $\left[t_{0}, \infty\right)$, and the condition

$$
\int_{\tau(t)}^{t} \mathcal{Q}(s) \Phi(\tilde{\mathcal{R}}(s)) d s \geq \varrho
$$

holds for some $\varrho>0$ and $a t$ that is large enough. Then,

$$
\frac{z^{\prime}(\tau(t))}{z^{\prime}(t)} \geq \Phi^{-1}\left(\frac{g_{n}(\varrho) r(t)}{r(\tau(t))}\right)
$$

for every $n$ and $t$ that are large enough, where $g_{n}(\varrho)$ is defined by (10).

Now, let us turn our attention to the Riccati technique. By our assumptions, conditions (2)-(4) hold, and we suppose that Equation (1) has an eventually positive solution $x(t)$. Take

$$
w(t)=r(t) \Phi\left(\frac{z^{\prime}(t)}{z(\tau(t))}\right) .
$$

By a direct differentiation, we have

$$
w^{\prime}(t)=\frac{\left(r(t) \Phi\left(z^{\prime}(t)\right)\right)^{\prime}}{\Phi(z(\tau(t))}-(p-1) r(t) \tau^{\prime}(t) \frac{\Phi\left(z^{\prime}(t)\right) z^{\prime}(\tau(t))}{|z(\tau(t))|^{p}}
$$


which, with the use of (9), gives

$$
w^{\prime}(t) \leq-c(t) \Phi(1-b(\tau(t)))-(p-1) r^{1-q}(t) \tau^{\prime}(t) \frac{z^{\prime}(\tau(t))}{z^{\prime}(t)}|w(t)|^{q} .
$$

Assuming that there exists a positive function $f(t)$ (one possible choice is $\Phi^{-1}\left(\frac{r(t)}{r(\tau(t))}\right)$ by (8)) such that

$$
\frac{z^{\prime}(\tau(t))}{z^{\prime}(t)} \geq f(t)>0
$$

we obtain the Riccati-type inequality of the form

$$
w^{\prime}(t) \leq-c(t) \Phi(1-b(\tau(t)))-(p-1) r^{1-q}(t) \tau^{\prime}(t) f(t)|w(t)|^{q} .
$$

Next, we introduce the modified Riccati technique. Let $h(t)$ be a positive differentiable function, and put

$$
G(t)=r(t) h(\tau(t)) \Phi\left(\frac{h^{\prime}(\tau(t))}{f(t)}\right) .
$$

Using the modified Riccati transformation

$$
v(t)=h^{p}(\tau(t)) w(t)-G(t),
$$

we obtain the so-called modified Riccati inequality (18) that is derived in the next lemma.

Lemma 3. Suppose that Equation (1) has an eventually positive solution $x(t)$ and $w$ is defined by (13). Let $f$ be a positive function satisfying (14), let $h$ be a positive differentiable function, and let $G$ be defined by (16). Then, the function $v(t)$, given by (17), satisfies the inequality

$$
v^{\prime}(t)+C(t)+(p-1) r^{1-q}(t) \tau^{\prime}(t) h^{-q}(\tau(t)) f(t) H(v(t), G(t)) \leq 0,
$$

where

$$
C(t)=h(\tau(t))\left[\left(r(t) \Phi\left(\frac{h^{\prime}(\tau(t))}{f(t)}\right)\right)^{\prime}+c(t) \Phi(h(\tau(t))) \Phi(1-b(\tau(t)))\right]
$$

and

$$
H(v, G)=|v+G|^{q}-q \Phi^{-1}(G) v-|G|^{q} .
$$

Proof. By a direct differentiation, we obtain

$$
\begin{aligned}
v^{\prime}(t) & =p h^{p-1}(\tau(t)) h^{\prime}(\tau(t)) \tau^{\prime}(t) w(t)+h^{p}(\tau(t)) w^{\prime}(t)-G^{\prime}(t) \\
& =p h^{\prime}(\tau(t)) \tau^{\prime}(t) h^{-1}(\tau(t))(v(t)+G(t))+h^{p}(\tau(t)) w^{\prime}(t)-G^{\prime}(t),
\end{aligned}
$$

and with the use of (15), we have (suppressing the argument $t$ )

$$
\begin{aligned}
v^{\prime} & \leq p h^{\prime}(\tau) \tau^{\prime} h^{-1}(\tau)(v+G)-G^{\prime}+h^{p}(\tau)\left[-c \Phi(1-b(\tau))-(p-1) r^{1-q} \tau^{\prime} f|w|^{q}\right] \\
& =p h^{\prime}(\tau) \tau^{\prime} h^{-1}(\tau)(v+G)-G^{\prime}-h^{p}(\tau) c \Phi(1-b(\tau))-(p-1) r^{1-q} \tau^{\prime} h^{-q}(\tau) f|v+G|^{q} \\
& =-\tilde{C}-(p-1) r^{1-q} \tau^{\prime} h^{-q}(\tau) f\left[|v+G|^{q}-q \Phi^{-1}(G) v-|G|^{q}\right],
\end{aligned}
$$


where

$$
\begin{aligned}
\tilde{C}=- & p h^{\prime}(\tau) \tau^{\prime} h^{-1}(\tau)(v+G)+G^{\prime}+h^{p}(\tau) c \Phi(1-b(\tau)) \\
& \quad+(p-1) r^{1-q} \tau^{\prime} h^{-q}(\tau) f\left[q \Phi^{-1}(G) v+|G|^{q}\right] \\
= & h^{p}(\tau) c \Phi(1-b(\tau))+G^{\prime}-p h^{\prime}(\tau) \tau^{\prime} h^{-1}(\tau) v-p h^{\prime}(\tau) \tau^{\prime} h^{-1}(\tau) r h(\tau) \Phi\left(\frac{h^{\prime}(\tau)}{f}\right) \\
& \quad+p r^{1-q} \tau^{\prime} h^{-q}(\tau) f r^{q-1} h^{q-1}(\tau) \frac{h^{\prime}(\tau)}{f} v+(p-1) r^{1-q} \tau^{\prime} h^{-q}(\tau) f r^{q} h^{q}(\tau) \frac{\left|h^{\prime}(\tau)\right|^{p}}{f^{p}} \\
= & h^{p}(\tau) c \Phi(1-b(\tau))+G^{\prime}-r\left|h^{\prime}(\tau)\right|^{p} \tau^{\prime} f^{1-p} .
\end{aligned}
$$

Since

$$
G^{\prime}(t)=\left(r(t) \Phi\left(\frac{h^{\prime}(\tau(t))}{f(t)}\right)\right)^{\prime} h(\tau(t))+r(t)\left|h^{\prime}(\tau(t))\right|^{p} \tau^{\prime}(t) f^{1-p}(t),
$$

we have

$$
\begin{aligned}
\tilde{C}(t) & =h^{p}(\tau(t)) c(t) \Phi(1-b(\tau(t)))+\left(r(t) \Phi\left(\frac{h^{\prime}(\tau(t))}{f(t)}\right)\right)^{\prime} h(\tau(t)) \\
& =h(\tau(t))\left[\left(r(t) \Phi\left(\frac{h^{\prime}(\tau(t))}{f(t)}\right)\right)^{\prime}+c(t) \Phi(h(\tau(t))) \Phi(1-b(\tau(t)))\right] .
\end{aligned}
$$

Hence, $\tilde{C}(t)=C(t)$ and the lemma is proved.

Similarly to in [18], we have the following two statements. In the first one, we formulate estimates for the function $H(v, G)$ from (20). Note that by applying these estimates in (18), we obtain an inequality that is, in fact, the Riccati inequality associated with a certain ordinary linear equation. The second statement gives sufficient conditions for the eventual non-negativity of the solutions to (18). By studying the proof of the original statement in [18], one can easily see that it also holds for the neutral version of the modified Riccati inequality (18).

Lemma 4 ([21], Lemma 5 and Lemma 6). The function $H(v, G)$ defined by (20) is non-negative and $H(v, G)=0$ if and only if $v=0$. Furthermore, if $\liminf _{t \rightarrow \infty}|G(t)|>0$ and $v(t) \rightarrow 0$ for $t \rightarrow \infty$, then

$$
H(v(t), G(t))=\frac{q(q-1)}{2}|G(t)|^{q-2} v^{2}(t)(1+o(1)), \quad \text { as } t \rightarrow \infty .
$$

Finally, for every $T>0$, there exists a constant $K>0$ such that

$$
H(v(t), G(t)) \geq K|G(t)|^{q-2} v^{2}(t)
$$

for any $t$ and $v$ satisfying $|v(t) / G(t)| \leq T$.

Lemma 5 ([18], Lemma 2.5). Let $h$ be a positive continuously differentiable function such that $h^{\prime} \neq 0$ for large $t$ and $C(t) \geq 0$ for large $t$. Moreover, let either

$$
\limsup _{t \rightarrow \infty}|G(t)|<\infty
$$

and

$$
\int^{\infty} \frac{f(t) \tau^{\prime}(t)}{r^{q-1}(t) h^{q}(\tau(t))} d t=\infty
$$

or

$$
\lim _{t \rightarrow \infty}|G(t)|=\infty
$$


and

$$
\int^{\infty} \frac{\Phi(f(t)) \tau^{\prime}(t)}{r(t) h^{2}(\tau(t))\left|h^{\prime}(\tau(t))\right|^{p-2}} d t=\infty .
$$

Then, all possible proper solutions (i.e., solutions that exist in a neighborhood of infinity) of (18) are eventually nonnegative.

\section{Main Results}

Theorem 1. Let $f$ be a positive function, let $G$ and $H$ be defined by (16) and (20), respectively, and let the conditions of Lemma 5 be satisfied. If

$$
\int^{\infty} C(t) d t=\infty,
$$

then Equation (1) is either oscillatory or, in every neighborhood of $\infty$, there exists $t^{*}$ such that $\frac{z^{\prime}\left(\tau\left(t^{*}\right)\right)}{z^{\prime}\left(t^{*}\right) f\left(t^{*}\right)}<1$ for all solutions of $(1)$.

Proof. Suppose, by a contradiction, that there exists $T \geq t_{0}$ such that (1) has a solution $x(t)$ that is positive for $t \in[T, \infty)$, and condition (14) holds on this interval. Then, $v(t)$ defined by (17) satisfies (18), and hence,

$$
v^{\prime}(t) \leq-C(t)-(p-1) r^{1-q}(t) \tau^{\prime}(t) h^{-q}(\tau(t)) f(t) H(v(t), G(t)) .
$$

Integrating the inequality from $t_{1} \geq T$ to $t$, we get

$$
v(t) \leq v\left(t_{1}\right)-\int_{t_{1}}^{t} C(s) d s-(p-1) \int_{t_{1}}^{t} r^{1-q}(s) \tau^{\prime}(s) h^{-q}(\tau(s)) f(s) H(v(s), G(s)) d s .
$$

Since the last subtracted term is nonnegative, we have

$$
v(t) \leq v\left(t_{1}\right)-\int_{t_{1}}^{t} C(s) d s
$$

and letting $t \rightarrow \infty$, we are led to a contradiction with non-negativity of $v(t)$ by Lemma 5 .

Denote

$$
R(t)=r(t) \frac{1}{\tau^{\prime}(t)} h^{2}(\tau(t))\left|h^{\prime}(\tau(t))\right|^{p-2} f^{1-p}(t) .
$$

Under the assumptions of the paper, according to (8), we can take $f(t)=\Phi^{-1}\left(\frac{r(t)}{r(\tau(t))}\right)$ and the functions $G, C$, and $R$ to get the following form:

$$
\begin{aligned}
& G_{1}(t)=r(\tau(t)) h(\tau(t)) \Phi\left(h^{\prime}(\tau(t))\right), \\
& C_{1}(t)=h(\tau(t))\left[\left(r(\tau(t)) \Phi\left(h^{\prime}(\tau(t))\right)\right)^{\prime}+c(t) \Phi(h(\tau(t))) \Phi(1-b(\tau(t)))\right], \\
& R_{1}(t)=r(\tau(t)) \frac{1}{\tau^{\prime}(t)} h^{2}(\tau(t))\left|h^{\prime}(\tau(t))\right|^{p-2} .
\end{aligned}
$$

In this special case of the function $f$, we can formulate a version of Theorem 1 as follows.

Corollary 1. Let $h$ be a positive continuously differentiable function such that $h^{\prime} \neq 0$ for large $t$ and $C_{1}(t) \geq 0$ for large $t$. Moreover, let either

$$
\limsup _{t \rightarrow \infty}\left|G_{1}(t)\right|<\infty \text { and } \int^{\infty} \frac{\tau^{\prime}(t)}{r^{q-1}(\tau(t)) h^{q}(\tau(t))} d t=\infty
$$

or

$$
\lim _{t \rightarrow \infty}\left|G_{1}(t)\right|=\infty \text { and } \int^{\infty} R_{1}^{-1}(t) d t=\infty
$$


If

$$
\int^{\infty} C_{1}(t) d t=\infty
$$

then Equation (1) is oscillatory.

The second and last theorem is of the Hille-Nehari type and concerns the case where the integral in (25) is convergent. We present a version with the general function $f$, and $G, C$, and $R$ are given by (16), (19), and (26); however, one can also formulate the special case of the theorem with the function $f(t)=\Phi^{-1}\left(\frac{r(t)}{r(\tau(t))}\right)$ and $G_{1}, C_{1}$, and $R_{1}$, similarly to in Corollary 1. Recall that the same types of results for half-linear Equation (5) were proved in [26], and for delayed half-linear Equation (6), comparison theorems providing qualitatively similar results were presented in [18].

Theorem 2. Let $h$ be a positive continuously differentiable function such that $h^{\prime} \neq 0$ for large $t$ and let $f$ be a positive function such that $C(t) \geq 0$ for large $t, \int^{\infty} R^{-1}(t) d t=\infty, \liminf _{t \rightarrow \infty} G(t)>0$, and

$$
\limsup _{t \rightarrow \infty} G(t)<\infty \quad \text { or } \quad \lim _{t \rightarrow \infty} G(t)=\infty .
$$

Suppose that $\int^{\infty} C(t) d t<\infty$. If

$$
\liminf _{t \rightarrow \infty} \int^{t} R^{-1}(s) d s \int_{t}^{\infty} C(s) d s>\frac{1}{2 q},
$$

then Equation (1) is either oscillatory or in every neighborhood of $\infty$, there exists $t^{*}$ such that $\frac{z^{\prime}\left(\tau\left(t^{*}\right)\right)}{z^{\prime}\left(t^{*}\right) f\left(t^{*}\right)}<1$ for all solutions of $(1)$.

Proof. Suppose, by a contradiction, that there exists $T \geq t_{0}$ such that (1) has a solution $x(t)$ that is positive for $t \in[T, \infty)$, and condition (14) holds on this interval. All conditions of Lemma 5 are satisfied. Indeed, conditions (21) and (23) are given in (29), condition (24) is, in fact, $\int^{\infty} R^{-1}(t) d t=\infty$, and (22) can be written in the form $\int{ }^{\infty} R^{-1}(t)|G(t)|^{2-q} d t=\infty$; this follows from (24) and the fact that $0<\liminf _{t \rightarrow \infty}|G(t)| \leq \limsup _{t \rightarrow \infty}|G(t)|<\infty$. With respect to Lemma 5 , the function $v(t)$ defined by (17) is eventually non-negative. We show that $\lim _{t \rightarrow \infty} v(t)=0$. It follows from (18) that $v^{\prime}(t) \leq 0$; hence, the limit exists and is non-negative and finite. Integrating (18) from $T_{1}$ to $t\left(T_{1} \geq T\right)$ yields

$$
v\left(T_{1}\right)-v(t) \geq \int_{T_{1}}^{t} C(s) d s+(p-1) \int_{T_{1}}^{t} r^{1-q}(s) \tau^{\prime}(s) h^{-q}(\tau(s)) f(s) H(v(s), G(s)) d s .
$$

Since $v(t) \geq 0$, we have

$$
v\left(T_{1}\right) \geq \int_{T_{1}}^{t} C(s) d s+(p-1) \int_{T_{1}}^{t} r^{1-q}(s) \tau^{\prime}(s) h^{-q}(\tau(s)) f(s) H(v(s), G(s)) d s .
$$

Both the integrals in the inequality are non-negative, and letting $t \rightarrow \infty$, we see that the integral

$$
\int_{T_{1}}^{t} r^{1-q}(s) \tau^{\prime}(s) h^{-q}(\tau(s)) f(s) H(v(s), G(s)) d s
$$

is convergent. With respect to conditions $\liminf _{t \rightarrow \infty} G(t)>0$ and $\lim _{t \rightarrow \infty} v(t)<\infty$, there exists a positive constant $M$ and $T_{2} \geq T_{1}$ such that $\left|\frac{v(t)}{G(t)}\right|<M$ for $t \geq T_{2}$. According to Lemma 4, there exists $K>0$ such that

$$
K|G(t)|^{q-2} v^{2}(t) \leq H(v(t), G(t)) \quad \text { for } t \geq T_{2} .
$$


Since $R(t)|G(t)|^{q-2}=\frac{r^{q-1}(t) h^{q}(\tau(t))}{\tau^{\prime}(t) f(t)}$, we have

$$
K \frac{v^{2}(t)}{R(t)} \leq r^{1-q}(t) \tau^{\prime}(t) h^{-q}(\tau(t)) f(t) H(v(t), G(t)) \quad \text { for } t \geq T_{2} .
$$

Integrating the last inequality from $T_{3}$ to $t\left(T_{3} \geq T_{2}\right)$ and letting $t \rightarrow \infty$, we obtain

$$
K \int_{T_{3}}^{\infty} \frac{v^{2}(t)}{R(t)} d t \leq \int_{T_{3}}^{\infty} r^{1-q}(t) \tau^{\prime}(t) h^{-q}(\tau(t)) f(t) H(v(t), G(t)) d t<\infty .
$$

As $\int^{\infty} R^{-1}(t) d t=\infty$, the last inequality implies that $\lim _{t \rightarrow \infty} v(t)=0$.

Now, we integrate (18) from $t$ to $\infty$ to obtain

$$
v(t) \geq \int_{t}^{\infty} C(s) d s+(p-1) \int_{t}^{\infty} r^{1-q}(s) \tau^{\prime}(s) h^{-q}(\tau(s)) f(s) H(v(s), G(s)) d s .
$$

Let $\varepsilon>0$. According to Lemma 4 , there exists a $T_{4}$ large enough such that

$$
\begin{aligned}
H(v(t), G(t)) & \geq\left(\frac{q(q-1)}{2}-\varepsilon\right) v^{2}(t)|G(t)|^{q-2} \\
& =\left(\frac{q(q-1)}{2}-\varepsilon\right) r^{q-2}(t) h^{q-2}(\tau(t))\left|h^{\prime}(\tau(t))\right|^{2-p} f^{p-2}(t) v^{2}(t)
\end{aligned}
$$

for $t \geq T_{4}$. Hence,

$$
v(t) \geq \int_{t}^{\infty} C(s) d s+(p-1)\left(\frac{q(q-1)}{2}-\varepsilon\right) \int_{t}^{\infty} \frac{v^{2}(s)}{R(s)} d s
$$

for $t \geq T_{4}$. Denoting $\tilde{\varepsilon}=(p-1) \varepsilon$, the inequality becomes

$$
v(t) \geq \int_{t}^{\infty} C(s) d s+\left(\frac{q}{2}-\tilde{\varepsilon}\right) \int_{t}^{\infty} R^{-1}(s) v^{2}(s) d s
$$

and multiplication by $\mathcal{R}(t)=\int^{t} R^{-1}(s) d s$ gives

$$
\mathcal{R}(t) v(t) \geq \mathcal{R}(t) \int_{t}^{\infty} C(s) d s+\left(\frac{q}{2}-\tilde{\varepsilon}\right) \mathcal{R}(t) \int_{t}^{\infty} \frac{R^{-1}(s)}{\mathcal{R}^{2}(s)}(\mathcal{R}(s) v(s))^{2} d s
$$

With respect to (30), there exists $\delta>0$ such that $\liminf _{t \rightarrow \infty} \mathcal{R}(t) \int_{t}^{\infty} C(s) d s \geq \frac{1}{2 q}+\delta$. Furthermore, we observe that $\mathcal{R}(t) \int_{t}^{\infty} \frac{R^{-1}(s)}{\mathcal{R}^{2}(s)} d s=1$. There are two possible options: either $\liminf _{t \rightarrow \infty} \mathcal{R}(t) v(t)<\infty$ or $\liminf _{t \rightarrow \infty} \mathcal{R}(t) v(t)=\infty$. Let us discuss both cases.

(a) Suppose that $\liminf _{t \rightarrow \infty} \mathcal{R}(t) v(t):=L<\infty$. From (31), one can see that $L>0$. For every $\bar{\varepsilon}>0$, there exists a $T_{5}$ large enough so that $(\mathcal{R}(t) v(t))^{2}>(1-\bar{\varepsilon})^{2} L^{2}$ for $t \geq T_{5}$. Estimations of the terms in (31) give

$$
(1+\bar{\varepsilon}) L \geq \frac{1}{2 q}+\delta+\left(\frac{q}{2}-\tilde{\varepsilon}\right)(1-\bar{\varepsilon})^{2} L^{2}
$$

Letting $\tilde{\varepsilon}, \bar{\varepsilon} \rightarrow 0$ gives a contradiction, since then,

$$
L \geq \frac{1}{2 q}+\delta+\frac{q}{2} L^{2} \Leftrightarrow \frac{q}{2}\left(L-\frac{1}{q}\right)^{2}+\delta \leq 0 .
$$

(b) In the case where $\liminf _{t \rightarrow \infty} \mathcal{R}(t) v(t)=\infty$, we denote $m(t)=\inf _{t \leq s}\{\mathcal{R}(s) v(s)\}$. Then, from (31), it follows that 


$$
\mathcal{R}(t) v(t) \geq \frac{1}{2 q}+\delta+\left(\frac{q}{2}-\tilde{\varepsilon}\right) m^{2}(t) .
$$

Since the function $m$ is nondecreasing, we have for $s \geq t$ :

$$
\mathcal{R}(s) v(s) \geq \frac{1}{2 q}+\delta+\left(\frac{q}{2}-\tilde{\varepsilon}\right) m^{2}(s) \geq \frac{1}{2 q}+\delta+\left(\frac{q}{2}-\tilde{\varepsilon}\right) m^{2}(t),
$$

and hence,

$$
m(t) \geq \frac{1}{2 q}+\delta+\left(\frac{q}{2}-\tilde{\varepsilon}\right) m^{2}(t)>\left(\frac{q}{2}-\tilde{\varepsilon}\right) m^{2}(t),
$$

which gives a contradiction with the assumption $\liminf _{t \rightarrow \infty} \mathcal{R}(t) v(t)=\infty$.

The proof is finished.

\section{Examples}

Consider the Euler-type equation

$$
\left(\Phi\left(x(t)+b_{0} x(\sigma(t))\right)^{\prime}\right)^{\prime}+\frac{\gamma}{t^{p}} \Phi(x(\lambda t))=0,
$$

where $\lambda \in(0,1), \sigma(t) \leq t, \lim _{t \rightarrow \infty} \sigma(t)=\infty$, and $b_{0} \in[0,1)$. Equation (32) is of the form (1), where $r(t)=1, c(t)=\frac{\gamma}{t^{p}}, \tau(t)=\lambda t$, and $b(t)=b_{0}$.

Example 1. Take $h(t)=t^{\frac{p-1}{p}}$; then, by a direct computation, we have

$$
G_{1}(t)=\left(\frac{p-1}{p}\right)^{p-1}, \quad R_{1}(t)=\left(\frac{p-1}{p}\right)^{p-2} t
$$

and

$$
\int^{\infty} \frac{\tau^{\prime}(t)}{r^{q-1}(\tau(t)) h^{q}(\tau(t))} d t=\int^{\infty} \frac{1}{t} d t \rightarrow \infty
$$

Hence, condition (27) is satisfied. Furthermore, we have

$$
\begin{aligned}
C_{1}(t) & =(\lambda t)^{\frac{p-1}{p}}\left[\left(\left(\frac{p-1}{p}\right)^{p-1}(\lambda t)^{\frac{1-p}{p}}\right)^{\prime}+c(t) \Phi\left(1-b_{0}\right)\left((\lambda t)^{\frac{p-1}{p}}\right)^{p-1}\right] \\
& =(\lambda t)^{\frac{p-1}{p}}\left[-\left(\frac{p-1}{p}\right)^{p} \lambda^{\frac{1}{p}-1} t^{\frac{1}{p}-2}+c(t) \Phi\left(1-b_{0}\right)(\lambda t)^{p-2+\frac{1}{p}}\right] \\
& =t^{-1}\left[-\left(\frac{p-1}{p}\right)^{p}+c(t) \Phi\left(1-b_{0}\right) \lambda^{p-1} t^{p}\right] \\
& =t^{-1}\left[-\left(\frac{p-1}{p}\right)^{p}+\gamma \Phi\left(1-b_{0}\right) \lambda^{p-1}\right] .
\end{aligned}
$$

The positivity of the expression $-\left(\frac{p-1}{p}\right)^{p}+\gamma \Phi\left(1-b_{0}\right) \lambda^{p-1}$ implies (28). So, by Corollary 1, Equation (32) is oscillatory if

$$
\gamma>\left(\frac{p-1}{p}\right)^{p} \frac{1}{\lambda^{p-1} \Phi\left(1-b_{0}\right)} .
$$

This corresponds to the result known in the case where $b_{0}=0$ (equations with delay, see [18]) and also with the case where $b_{0}=0$ and $\lambda=1$ (ordinary equations). 
Example 2. Condition (35) can even be strengthened for a class of Equation (32), which satisfies (12) with $\varrho \in\left(0, \frac{1}{e}\right)$. By a direct computation (or see [10]), one can show that for (32),

$$
\varrho=\left(1-b_{0}\right)^{p-1} \gamma \lambda^{p-1}\left(1+\frac{1}{p-1} \lambda^{p-1}\left(1-b_{0}\right)^{p-1} \gamma\right)^{p-1} \log \left(\frac{1}{p-1}\right) .
$$

Note that here and in what follows, the symbol log stands for the natural logarithm. If $\varrho \in$ $\left(0, \frac{1}{e}\right)$, according to Lemma 2, we can use in place of the positive function $f(t)$ from (14) the function $\Phi^{-1}\left(\frac{g(\rho) r(t)}{r(\tau(t))}\right)$, where $g(\varrho)$ is defined by (11). Then, functions $R, G$, and C become

$$
\begin{aligned}
& G_{2}(t)=r(\tau(t)) h(\tau(t)) \Phi\left(h^{\prime}(\tau(t))\right)(g(\varrho))^{-1}, \\
& C_{2}(t)=h(\tau(t))\left[\left(r(\tau(t)) \frac{\Phi\left(h^{\prime}(\tau(t))\right)}{g(\varrho)}\right)^{\prime}+c(t) \Phi(h(\tau(t))) \Phi\left(1-b_{0}\right)\right], \\
& R_{2}(t)=r(\tau(t)) \frac{1}{\tau^{\prime}(t)} h^{2}(\tau(t))\left|h^{\prime}(\tau(t))\right|^{p-2}(g(\varrho))^{-1} .
\end{aligned}
$$

In our setting for Equation (32) and again with $h(t)=t^{\frac{p-1}{p}}$, these read as

$$
G_{2}(t)=\left(\frac{p-1}{p}\right)^{p-1}(g(\varrho))^{-1}, \quad R_{1}(t)=\left(\frac{p-1}{p}\right)^{p-2}(g(\varrho))^{-1} t
$$

and

$$
C_{2}(t)=t^{-1}\left[-\left(\frac{p-1}{p}\right)^{p}(g(\varrho))^{-1}+\gamma \Phi\left(1-b_{0}\right) \lambda^{p-1}\right] .
$$

Since (21) and (22) hold and (25) is implied by the positivity of the expression

$$
\left[-\left(\frac{p-1}{p}\right)^{p}(g(\varrho))^{-1}+\gamma \Phi\left(1-b_{0}\right) \lambda^{p-1}\right]
$$

Equation (32) is oscillatory, according to Theorem 1, provided that

$$
\gamma>\left(\frac{p-1}{p}\right)^{p} \frac{1}{(g(\varrho)) \lambda^{p-1} \Phi\left(1-b_{0}\right)} .
$$

This corresponds to the condition derived in [10].

In the theory of ordinary equations, i.e., in the case where $\lambda=1$ and $b_{0}=0$ in (32), it is known that Equation (32) oscillates if and only if (35) holds. This means that the constant $\gamma=\left(\frac{p-1}{p}\right)^{p}$ is the critical constant between oscillation and non-oscillation of (32), and it is natural to study perturbations of the Euler-type equation with this critical constant and to find critical constants in the added terms. This corresponds to the concept of conditional oscillation (for details, see [23,27] and the references given therein). In the case of the delayed and neutral equations, there is not such a boundary between oscillation and nonoscillation of (32). However, based on the results known from the ordinary case, let us study the neutral version of the Euler-Weber-type equation

$$
\left(\Phi\left(x(t)+b_{0} x(\sigma(t))\right)^{\prime}\right)^{\prime}+\left(\frac{\left(\frac{p-1}{p}\right)^{p}}{\lambda^{p-1} \Phi\left(1-b_{0}\right) t^{p}}+\frac{\mu}{t^{p} \log ^{2} t}\right) \Phi(x(\lambda(t))=0 .
$$


Example 3. For (36), we use Theorem 2 with $f(t)=\Phi^{-1}\left(\frac{r(t)}{r(\tau(t))}\right)$. Similarly to in Example 1, we take $h(t)=t^{\frac{p-1}{p}}$, we obtain (33), and, with the use of the relevant coefficient function $c(t)$ in (34), we have

$$
C_{1}(t)=\frac{\mu}{t \log ^{2} t} \Phi\left(1-b_{0}\right) \lambda^{p-1}
$$

and

$$
\int_{t}^{\infty} C_{1}(s) d s=\int_{t}^{\infty} \frac{\mu \Phi\left(1-b_{0}\right) \lambda^{p-1}}{s \log ^{2} s} d s=\frac{\mu \Phi\left(1-b_{0}\right) \lambda^{p-1}}{\log t}
$$

Since $R_{1}^{-1}=\left(\frac{p}{p-1}\right)^{p-2} \frac{1}{t}$, condition (30) becomes

$$
\left(\frac{p}{p-1}\right)^{p-2} \mu \Phi\left(1-b_{0}\right) \lambda^{p-1}>\frac{1}{2 q}
$$

which, by Theorem 2, implies that Equation (36) is oscillatory if

$$
\mu>\frac{1}{2 \Phi\left(1-b_{0}\right) \lambda^{p-1}}\left(\frac{p-1}{p}\right)^{p-1}
$$

Note that in the ordinary case where $\lambda=1$ and $b_{0}=0$, the constant from (37) is critical, which means that (36) is oscillatory if and only if $\mu>\frac{1}{2}\left(\frac{p-1}{p}\right)^{p-1}$.

Example 4. Let us consider the perturbation of the Euler-Weber equation. Take $h(t)=t^{\frac{p-1}{p}} \log ^{\frac{1}{p}} t$ and consider Equation (1) with $r(t)=1, \tau(t)=\lambda t$, and $b(t)=0$. Observe that

$$
h^{\prime}(t)=\frac{p-1}{p} t^{-\frac{1}{p}} \log ^{\frac{1}{p}} t\left[1+\frac{1}{(p-1) \log t}\right] .
$$

By a direct computation, we see that

$$
\begin{aligned}
G_{1}(t) & =\left(\frac{p-1}{p}\right)^{p-1} \log (\lambda t)(1+o(1)), \\
R_{1}(t) & =\left(\frac{p-1}{p}\right)^{p-2} t \log (\lambda t)(1+o(1))
\end{aligned}
$$

as $t \rightarrow \infty$. With the use of the power expansion formula

$$
(1+x)^{s}=1+s x+\frac{s(s-1)}{2} x^{2}+\frac{s(s-1)(s-2)}{6} x^{3}+o\left(x^{3}\right) \text { as } x \rightarrow 0,
$$

one can show that for

$$
c(t)=\left(\frac{p}{p-1}\right)^{p} \frac{1}{\lambda^{p-1} t^{p}}+\frac{1}{2}\left(\frac{p}{p-1}\right)^{p-1} \frac{1}{\lambda^{p-1} t^{p} \log ^{2}(\lambda t)}+\frac{\mu}{t^{p} \log ^{2}(\lambda t) \log ^{2}(\log (\lambda t))},
$$

we have

Because

$$
C_{1}(t)=\frac{\mu \lambda^{p-1}}{t \log (\lambda t) \log ^{2}(\log (\lambda t))}(1+o(1)) \quad \text { as } t \rightarrow \infty
$$

$$
\int R_{1}^{-1}(t) d t \sim\left(\frac{p-1}{p}\right)^{2-p} \log (\log (\lambda t))
$$


and

$$
\int C_{1}(t) d t \sim-\frac{\mu \lambda^{p-1}}{\log (\log (\lambda t))}
$$

condition (30) becomes

$$
\left(\frac{p-1}{p}\right)^{2-p} \mu \lambda^{p-1}>\frac{1}{2 q} .
$$

Since $\frac{1}{q}=\frac{p-1}{p}$, the considered equation is oscillatory if

$$
\mu>\frac{1}{2}\left(\frac{p-1}{p}\right)^{p-1} \frac{1}{\lambda^{p-1}} .
$$

\section{Conclusions}

The aim of this paper was to study how the modified Riccati technique can be applied to Equation (1), which has not been tried for neutral equations before, and what results this approach can provide. According to our results, the modified Riccati method is applicable to Equation (1), and it can be used to find new criteria, for whose proofs it is enough to manipulate the modified Riccati inequality. We have presented two new oscillation criteria and illustrated their uses in examples dealing with a half-linear Euler-type equation and its perturbations.

Author Contributions: The authors contributed equally. All authors have read and agreed to the published version of the manuscript.

Funding: This research received no external funding.

Institutional Review Board Statement: Not applicable.

Informed Consent Statement: Not applicable.

Data Availability Statement: Not applicable.

Conflicts of Interest: The authors declare no conflict of interest.

\section{References}

1. Burton, T.A.; Purnaras, I.K. A unification theory of Krasnoselskii for differential equations. Nonlinear Anal. 2013, 89, 121-133. [CrossRef]

2. Smith, F.E. Population dynamics in Daphnia magna and a new model for population growth. Ecology 1963, 44, 651-663. [CrossRef]

3. Bohner, M.; Hassan, T.S.; Li, T. Fite-Hille-Wintner-type oscillation criteria for second-order half-linear dynamic equations with deviating arguments. Indag. Math. 2018, 29, 548-560. [CrossRef]

4. Hale, J.K.; Lunel, S.M.V. Introduction to Functional Differential Equations; Springer: Berlin/Heidelberg, Germany, 1993.

5. Li, T.; Pintus, N.; Viglialoro, G. Properties of solutions to porous medium problems with different sources and boundary conditions. Z. Angew. Math. Phys. 2019, 70, 86. [CrossRef]

6. Wong, J.S.W. On the generalized Emden-Fowler equation. SIAM Rev. 1975, 17, 339-360. [CrossRef]

7. Baculíková, B.; Džurina, J. Oscillation theorems for second-order nonlinear neutral differential equations. Comput. Math. Appl. 2011, 62, 4472-4478. [CrossRef]

8. Chatzarakis, G.E.; Grace, S.R. Third-order nonlinear differential equations with nonlinear neutral terms. Funct. Differ. Equ. 2020, 27, 3-13.

9. Fišnarová, S.; Mařík, R. Oscillation of second order half-linear neutral differential equations with weaker restrictions on shifted arguments. Math. Slovaca 2020, 70, 389-400. [CrossRef]

10. Grace, S.R.; Džurina, J.; Jadlovská, I.; Li, T. An improved approach for studying oscillation of second-order neutral delay differential equations. J. Inequal. Appl. 2018, 193, 1-13. [CrossRef]

11. Santra, S.S.; Gosh, T.; Bazighifan, T. Explicit criteria for the oscillation of second-order differential equations with several sub-linear neutral coefficients. Adv. Differ. Equ. 2020, 643, 1-12. [CrossRef]

12. Bohner, M.; Grace, S.R.; Jadlovská, I. Oscillation criteria for second-order neutral delay differential equations. Electron. J. Qual. Theory Differ. Equ. 2017, 60, 1-12. [CrossRef]

13. Chatzarakis, G.E.; Džurina, J.; Jadlovská, I. A remark on oscillatory results for neutral differential equations. Appl. Math. Lett. 2019, 90, 124-130. [CrossRef] 
14. Chatzarakis, G.E.; Džurina, J.; Jadlovská, I. New oscillation criteria for second-order half-linear advanced differential equations. Appl. Math. Comput. 2019, 347, 404-416. [CrossRef]

15. Drábek, P.; Kufner, A.; Kuliev, K. Oscillation and nonoscillation results for solutions of half-linear equations with deviated argument. J. Math. Anal. Appl. 2017, 447, 371-382. [CrossRef]

16. Džurina, J.; Jadlovská, I. A note on oscillation of second-order delay differential equations. Appl. Math. Lett. 2017, 69, 126-132. [CrossRef]

17. Džurina, J.; Stavroulakis, I.P. Oscillation criteria for second-order delay differential equations. Appl. Math. Comput. 2003, 140, 445-453. [CrossRef]

18. Fišnarová, S.; Mařík, R. Modified Riccati technique for half-linear differential equations with delay. Electron. J. Qual. Theory Differ. Equ. 2014, 64, 1-14. [CrossRef]

19. Jadlovská, I.; Džurina, J. Kneser-type oscillation criteria for second-order half-linear delay differential equations. Appl. Math. Comput. 2020, 380, 125289. [CrossRef]

20. Sun, Y.G.; Meng, F.W. Note on the paper of Džurina and Starvoulakis. Appl. Math. Comput. 2006, 174, $1634-1641$.

21. Došlý, O.; Fišnarová, S. Half-linear oscillation criteria: Perturbation in term involving derivative. Nonlinear Anal. 2010, 73, 3756-3766. [CrossRef]

22. Došlý, O.; Fišnarová, S.; Rík, R.M. Power comparison theorems in half-linear oscillation theory. J. Math. Anal. Appl. 2013, 401, 611-619. [CrossRef]

23. Došlý, O.; Funková, H. Perturbations of half-linear Euler differential equation and transformations of modified Riccati equation. Abstr. Appl. Anal. 2012, 2012, 738472. [CrossRef]

24. Fišnarová, S.; Pátíková, Z. Hille-Nehari type criteria and conditionally oscillatory half-linear differential equations. Electron. J. Qual. Theory 2019, 71, 1-22. [CrossRef]

25. Zhang, B.G.; Zhou, Y. The distribution of zeros of solutions of differential equations with a variable delay. J. Math. Anal. Appl. 2001, 256, 216-228. [CrossRef]

26. Došlý, O.; Lomtatidze, A. Oscillation and nonoscillation criteria for half-linear second order differential equations. Hiroshima Math. J. 2006, 36, 203-219. [CrossRef]

27. Došlá, Z.; Hasil, P.; Matucci, S.; Veselý, M. Euler type linear and half-linear differential equations and their non-oscillation in the critical oscillation case. J. Inequal. Appl. 2019, 189, 1-30. [CrossRef] 